\title{
Potencial de la organogénesis como estrategia para la masificación in vitro de Persea lingue en la zona centro-sur de Chile
}

\author{
Potential of organogenesis as a strategy to the in vitro propagation of Persea lingue \\ in the south-central region of Chile
}

\author{
José Cob*a,c, Ana M Sabja $^{\text {, }}$, Darcy Ríos ${ }^{c}$, Antonio Larad, Pablo J Donosod, Luis Arias ${ }^{\mathrm{e}}$, Bernardo Escobard \\ *Autor de correspondencia: aUniversidad Austral de Chile, Facultad de Ciencias Forestales y Recursos Naturales, \\ Valdivia, Chile, tel.: 5663 221491, josevidalc@yahoo.es \\ ${ }^{\mathrm{b}}$ GenFor S.A., Valdivia, Chile. \\ 'Universidad de Concepción, Facultad de Ciencias Forestales, Concepción, Chile. \\ dUniversidad Austral de Chile, Facultad de Ciencias Forestales y Recursos Naturales, Valdivia, Chile. \\ ${ }^{\text {e}}$ Centro de Investigación y de Estudios Avanzados-Unidad Mérida, México.
}

\begin{abstract}
SUMMARY
Lingue (Persea lingue) is a native arboreal species of Chile, adequate for producing high quality wood and also recognized for its beauty. The effect of supplemented hormonal components in the culture medium of the Persea lingue were studied, morphogenetic capacity and the in vitro regeneration process via histological studies were analyzed. The Murashige and Skoog (MS) basic culture medium was used and complemented with different concentrations of indole 3-butyric acid (IBA) and 6- Benzylaminopurine (BAP) using apical sections of microshoots obtained from in vitro germinated mature embryos. A complete random block design was applied with five repetitions and factorial arrangement of treatments, the experimental unit was a culture recipient containing one explant. The variance analysis showed statistically significant differences $(P=0.001)$ of the treatment factor on the above response, variable number of buds per explant and caulinary elongation. Regarding Duncan's multiple range test, it was possible to confirm that the treatments with significant differences were $0.1 \mathrm{mg} \mathrm{L}^{-1}$ of IBA and $2.0 \mathrm{mg} \mathrm{L}^{-1}$ of BAP for the induction of buds per explant and $0.05 \mathrm{mg} \mathrm{L}^{-1}$ of IBA and $0.5 \mathrm{mg} \mathrm{L}^{-1}$ of BAP for caulinary elongation. The histological analyses revealed that the proliferation of meristematic cells was originated in the epidermic and subepidermic tissue. As well, the study confirmed in vitro regeneration process through direct organogenesis. These results ratify that organogenesis can be a potential biotechnological tool, useful for massive rescue, conservation, and propagation of native species under a critical status.
\end{abstract}

Key words: auxins, cytokinins, caulinary elongation, in vitro propagation.

\section{RESUMEN}

Persea lingue (lingue) es una especie arbórea nativa de Chile apta para producir madera de alta calidad y belleza. El presente estudio evaluó el efecto de componentes hormonales suplementado con medios de cultivo sobre la capacidad morfogénica de Persea lingue y se analizó el proceso de regeneración in vitro mediante estudios histológicos. Se ensayó el medio de cultivo básico Murashige y Skoog (MS) complementado con diferentes concentraciones de ácido indol 3-butírico (AIB) y 6-bencilaminopurina (BAP), usando secciones apicales de microtallos obtenidos de embriones maduros germinados in vitro. Se utilizó un diseño en bloques completos aleatorizados con cinco repeticiones y arreglo factorial de tratamientos; la unidad experimental fue un recipiente de cultivo conteniendo un explante. Hubo efectos significativos $(P=0,001)$ del tratamiento sobre las variables respuesta número de yemas, número de brotes y elongación caulinar. La prueba de rangos múltiples de Duncan confirmó que los tratamientos que observaron diferencias significativas fueron $0,1 \mathrm{mg} \mathrm{L}^{-1}$ de AIB y $2,0 \mathrm{mg} \mathrm{L}^{-1}$ de BAP para la inducción de yemas por explante y $0,05 \mathrm{mg} \mathrm{L}^{-1}$ de AIB y $0,5 \mathrm{mg} \mathrm{L}^{-1}$ de BAP para la elongación caulinar. El análisis histológico demostró que la proliferación de células meristemáticas se inició a partir del tejido epidérmico y subepidérmico. Asimismo, corroboró el proceso de regeneración in vitro vía organogénesis directa. Estos resultados ratifican a la organogénesis como una potencial herramienta biotecnológica útil para rescatar, conservar y propagar masivamente a esta especie nativa.

Palabras clave: auxinas, citoquininas, elongación caulinar, propagación in vitro.

\section{INTRODUCCIÓN}

Persea lingue Ness (lingue) es una especie arbórea que forma parte de los recursos fitogenéticos nativos de la zona centro-sur de Chile. Puede alcanzar dimensiones de hasta $30 \mathrm{~m}$ de altura y $80 \mathrm{~cm}$ de diámetro, en las mejores condiciones de sitio (Donoso 1974, Rodríguez et al. 1983, Donoso y Escobar 2006). En los individuos maduros, la corteza es muy característica, gruesa, rugosa y con protuberancias similares a verrugas uniformemente distribuidas con un alto contenido de taninos (cerca del $25 \%$ ), por lo que se emplea en la industria de la curtiduría. Además, 
es una especie apta para producir madera de alta calidad y belleza, aprovechada en la mueblería, tornería y en la construcción (Donoso y Escobar 2006).

Por otro lado, la explotación irracional que sufrió Persea lingue en el pasado, mediante la extracción indiscriminada de individuos, el cambio de uso del suelo y la frecuencia de incendios han generado poblaciones de lingue altamente fragmentadas, aumentando su aislamiento y propiciando un incremento en el riesgo de extinción de esta especie (Bustamante y Castor 1998, Bennett 1988, Bustamante et al. 2003, Echeverría et al. 2006). Aunado a lo anterior, en los métodos de propagación tradicional de esta especie existen limitaciones y dificultades tales como lentitud en el proceso de germinación, obtención de semillas a intervalos irregulares y una baja energía germinativa (Escobar et al. 1998, Donoso y Escobar 2006). Bajo este escenario, el cultivo in vitro se propone como una excelente alternativa para superar algunas de las dificultades antes mencionadas (Hartmann y Kester 1999). Concretamente, la técnica de la organogénesis directa es una vía factible para incrementar de forma rápida el número de individuos, constituyendo una etapa importante para el establecimiento de un banco de germoplasma en especies amenazadas o en peligro de extinción (Uribe et al. 2008)

El presente estudio plantea como objetivo evaluar el efecto de componentes hormonales complementado con medios de cultivo sobre la capacidad morfogénica de Persea lingue y realizar estudios histológicos del proceso de regeneración in vitro. Específicamente, se pretende establecer concentraciones hormonales apropiadas para la obtención de microtallos enraizables. Lo anterior aportará cimientos científicos para el establecimiento de un banco de germoplasma libre de enfermedades y patógenos con fines futuros de recuperación, conservación y propagación in vitro de Persea lingue.

\section{MÉTODOS}

Material vegetal. Como material vegetal inicial se utilizaron frutos maduros de Persea lingue cosechados en el año 2008, provenientes de poblaciones creciendo bajo condiciones naturales en sitios circundantes a la ciudad de Valdivia, Chile $\left(39^{\circ} 49^{\prime} \text { S y } 73^{\circ} 14^{\prime} \mathrm{O}\right)^{1}$. Los frutos se mantuvieron remojados en agua corriente durante 24 horas. Seguidamente se colocaron bajo luz solar durante 12 horas para eliminar el pericarpio debido a que tiene un efecto inhibidor sobre la germinación de la semilla (Escobar 1998). A continuación, bajo cámara de flujo laminar se inició la asepsia superficial de las semillas mediante lavados en solución de etanol al $70 \%$ v/v durante cinco minutos, seguidos de dos enjuagues de tres minutos

\footnotetext{
El estudio se realizó en el laboratorio de micropropagación y biotecnología forestal de la empresa GenFor S. A., ubicado en la ciudad de Valdivia.
}

cada uno con agua destilada estéril. Posteriormente, las semillas fueron inmersas en una solución de hipoclorito de sodio $(\mathrm{NaClO})$ al $50 \%$ v/v más una gota de Tween 20 , manteniéndolas en agitación continua durante 20 minutos. Por último, se efectuaron tres enjuagues consecutivos con agua destilada estéril durante tres, cuatro y cinco minutos, respectivamente.

Con la ayuda de pinzas y bisturí, bajo una lupa estereoscópica, se procedió a la extracción de los embriones, los cuales fueron sembrados en tubos de ensayo conteniendo $15 \mathrm{~mL}$ de medio de cultivo gelificado con agar. Estos se mantuvieron en la cámara de crecimiento durante dos semanas en oscuridad a una temperatura de $25{ }^{\circ} \mathrm{C} \pm 1{ }^{\circ} \mathrm{C}$ hasta su germinación.

Medio de cultivo. En la etapa de establecimiento embrionario se utilizó el medio MS (Murashige y Skoog 1962) con sus macronutrientes reducidos a $1 / 4$, suplementado con sacarosa como fuente de carbono $\left(30 \mathrm{~g} \mathrm{~L}^{-1}\right)$, libre de hormonas, y ajustando el $\mathrm{pH}$ a 5,7 con $\mathrm{NaOH}$ (hidróxido de sodio). Como agente gelificante al medio nutritivo se adicionó agar $\left(7 \mathrm{~g} \mathrm{~L}^{-1}\right)$.

En una posterior etapa de proliferación, secciones apicales de microtallos de 7 a $8 \mathrm{~mm}$ de longitud logrados de embriones germinados in vitro fueron cultivados en el medio básico MS. Como fuente energética se agregó sacarosa $\left(30 \mathrm{~g} \mathrm{~L}^{-1}\right)$, ajustando el $\mathrm{pH}$ a 5,7 y gelificado con agar $\left(7 \mathrm{~g} \mathrm{~L}^{-1}\right)$. El medio nutritivo fue suplementado con una combinación y balance hormonal de ácido indolbutírico (AIB) y bencilaminopurina (BAP) (cuadro 1); como respuesta se evaluaron las variables número de yemas, número de brotes y número de hojas por explante. En la fase de elongación, las secciones apicales fueron cultivadas en el medio básico MS suplementado con tres concentraciones hormonales de AIB y BAP (cuadro 1); en esta fase, las variables que se cuantificaron fueron las longitudes de yemas, de brotes y de entrenudos por explante.

Cuadro 1. Tratamientos evaluados para la inducción de yemas y elongación de brotes en la propagación in vitro de Persea lingue.

Evaluated treatments for the induction of buds and shoot elongation at in vitro propagation of Persea lingue.

\begin{tabular}{lccc}
\hline \multirow{2}{*}{ Tratamientos } & $\begin{array}{c}\text { Etapa I } \\
\text { Establecimiento }\end{array}$ & $\begin{array}{c}\text { Etapa II } \\
\text { Proliferación }\end{array}$ & $\begin{array}{c}\text { Etapa III } \\
\text { Elongación }\end{array}$ \\
\cline { 2 - 4 } & Ácido indolbutírico/Bencilaminopurina $\left(\mathrm{mg} \mathrm{L}^{-1}\right)$ \\
\hline T1 & $0,0 / 0,0$ & $0,1 / 1,0$ & $0,01 / 0,1$ \\
T2 & $0,0 / 0,0$ & $0,1 / 2,0$ & $0,05 / 0,5$ \\
T3 & $0,0 / 0,0$ & $0,5 / 2,0$ & $0,10 / 1,0$ \\
\hline
\end{tabular}

Diseño experimental y análisis estadístico. El diseño experimental utilizado fue en bloques completos aleatorizados con cinco repeticiones y arreglo factorial de tratamientos. La unidad experimental fue un recipiente de cultivo conteniendo un explante, estableciéndose quince 
recipientes por cada tratamiento, los cuales fueron distribuidos aleatoriamente en cada bloque. Se realizó un análisis de varianza (ANDEVA) a través del procedimiento PROC GLM del programa estadístico SAS (Statistical Analysis System). Finalmente, la comparación de medias de los tratamientos se hizo mediante la prueba de rangos múltiples de Duncan.

Estudio histológico. Para el análisis histológico, se tomaron cuatro muestras durante las etapas de proliferación y elongación. Las muestras fueron fijadas entre 24 y 48 horas en FAA [formalina (5\%)-ácido acético (5\%)-alcohol etílico $(90 \%)$ ]. Posteriormente, se lavaron con agua corriente durante 24 horas. Una vez concluido el lavado, el tejido fue deshidratado en soluciones seriadas de alcohol etílico (50, 75,85 y $95 \%$ ) cada dos horas. Seguidamente, las muestras se pasaron tres veces por alcohol etílico puro, durante dos horas, en los primeros dos pases y, durante toda la noche, en el último pase. Luego se realizaron tres inmersiones en xilol por dos horas en cada pase y se impregnaron en tres pases de parafina cada dos horas. A continuación las muestras se incluyeron en bloques de parafina a los que se les realizaron cortes en secciones transversales y longitudinales con un grosor de 5-8 $\mu \mathrm{m}$ utilizando un micrótomo de deslizamiento vertical. Finalmente, cada corte fue adherido a un portaobjetos y teñido con azul de astra safranina al $1 \%$. Para la observación de las muestras se utilizó un microscopio Axioskop OPTON y las imágenes se fotografiaron con una cámara digital Canon Power Shot G5 adaptada al microscopio.

\section{RESULTADOS}

El proceso de germinación vía in vitro se inició 15 días después del establecimiento embrionario, observándose inicialmente la aparición del epicótilo. A los 30 días del establecimiento, se registró un $100 \%$ de emergencia de las vitroplantas. En ellas se observó un adecuado desarrollo del hipocótilo, de aspecto vigoroso, y no hubo presencia de contaminación fúngica o bacteriana (figura 1A).

Acorde a los resultados del ANDEVA, el factor bloque no presentó efecto significativo $(P>0,05, \mathrm{~F}=0,80$ y 1,21$)$. Lo anterior respalda que las fluctuaciones ambientales en las cámaras de crecimiento fueron estables, sugiriendo que el experimento pudo haberse realizado bajo un diseño completamente al azar. El factor tratamiento fue significativo $(P<0,001, \mathrm{~F}=62,00$ y 26,61$)$ sobre las variables respuesta número de yemas por explante y longitud de brotes, es decir, no hubo igualdad de medias entre los grupos de tratamientos estudiados.

En la etapa de proliferación, con relación a las variables número de yemas y brotes por explante, el tratamiento T2 $\left(0,1 / 2,0 \mathrm{mg} \mathrm{L}^{-1}\right)$ fue el que produjo un efecto positivo significativo. Esta combinación y balance hormonal permitió la mayor cantidad de yemas finales, con un promedio de nueve por explante a los 90 días de cultivo, las cuales generaron brotes de tallas homogéneas y de aspecto vigoroso (cuadro 2, figura $1 \mathrm{C}$ ). Lo anterior revela que los explantes en presencia de hormonas exógenas exhibieron múltiples puntos de crecimiento cambiando morfológicamente a brotes.

Con relación a los tratamientos compuestos por el balance hormonal 0,1/1,0 $\mathrm{mg} \mathrm{L}^{-1}$ y $0,5 / 2,0 \mathrm{mg} \mathrm{L}^{-1}$ el análisis demuestra que no hubo diferencias estadísticamente significativas entre ellos (cuadro 2). Particularmente, al tratamiento T1 (0,1/1,0 $\left.\mathrm{mg} \mathrm{L}^{-1}\right)$ se le disminuyó la concentración de la citoquinina en el medio de cultivo manteniendo los niveles de auxina análogo al tratamiento T2 $(0,1 / 2,0 \mathrm{mg}$ $\mathrm{L}^{-1}$ ), obteniéndose en promedio cuatro yemas por explante (cuadro 2). Al tratamiento T3 $\left(0,5 / 2,0 \mathrm{mg} \mathrm{L}^{-1}\right)$ se le redujo la concentración de la auxina en el medio nutritivo, manteniendo las proporciones de citoquinina, similar al tratamiento T2, lográndose en promedio tres yemas por explante (cuadro 2). No obstante, los microtallos que fueron cultivados en el tratamiento T1, compuesto por $0,1 / 1,0 \mathrm{mg}$ $\mathrm{L}^{-1}$ de ácido indolbutírico/bencilaminopurina observaron una acentuada aparición de hojas, una reducida cantidad de verticilos y la mayoría de aspecto y forma arrosetada (figura 1B). En cuanto a la variable número de hojas por explante, el tratamiento T1, constituido por la proporción hormonal 0,1/1,0 $\mathrm{mg} \mathrm{L}^{-1}$, favoreció la formación y mayor presencia de hojas, lográndose en promedio seis hojas por explante (cuadro 2).

En la etapa de elongación caulinar, el análisis mostró un efecto positivo significativo con bajas concentraciones hormonales complementadas en el medio nutritivo. Particularmente, el tratamiento hormonal T2 $\left(0,05 / 0,5 \mathrm{mgL}^{-1}\right)$ fue el que observó un efecto significativo sobre el desarrollo en longitud de los brotes. Bajo esta combinación y balance hormonal se lograron brotes cuyas longitudes en promedio fueron de $25 \mathrm{~mm}$, exhibiendo hojas de una coloración verde intenso y de aspecto vigoroso (cuadro 2, figura 1D).

Con relación a los tratamientos $\mathrm{T} 1\left(0,01 / 0,1 \mathrm{mg} \mathrm{L}^{-1}\right)$ y T3 $\left(0,10 / 1,0 \mathrm{mg} \mathrm{L}^{-1}\right)$ el análisis demostró que no hubo diferencias significativas (cuadro 2). Específicamente, los microtallos que fueron cultivados en el tratamiento T1 alcanzaron en promedio $16 \mathrm{~mm}$ de longitud y los cultivados en el tratamiento T3 lograron tallas en promedio de $15 \mathrm{~mm}$ (cuadro 2).

La estimulación en la longitud de los entrenudos bajo las proporciones hormonales analizadas presentó diferencias significativas (cuadro 2). El tratamiento hormonal T2 $\left(0,05 / 0,5 \mathrm{mg} \mathrm{L}^{-1}\right)$ fue el que favoreció un mejor desarrollo en longitud, apreciándose entrenudos que registraron en promedio cinco $\mathrm{mm}$ (cuadro 2). Con relación a los microtallos que fueron cultivados en los tratamientos T1 $\left(0,01 / 0,1 \mathrm{mg} \mathrm{L}^{-1}\right)$ y T3 $\left(0,10 / 1,0 \mathrm{mg} \mathrm{L}^{-1}\right)$ exhibieron entrenudos con promedios de tres y dos $\mathrm{mm}$ de longitud (cuadro 2). Con tales resultados se fundamenta que la elongación caulinar se restringió al aumentar la 


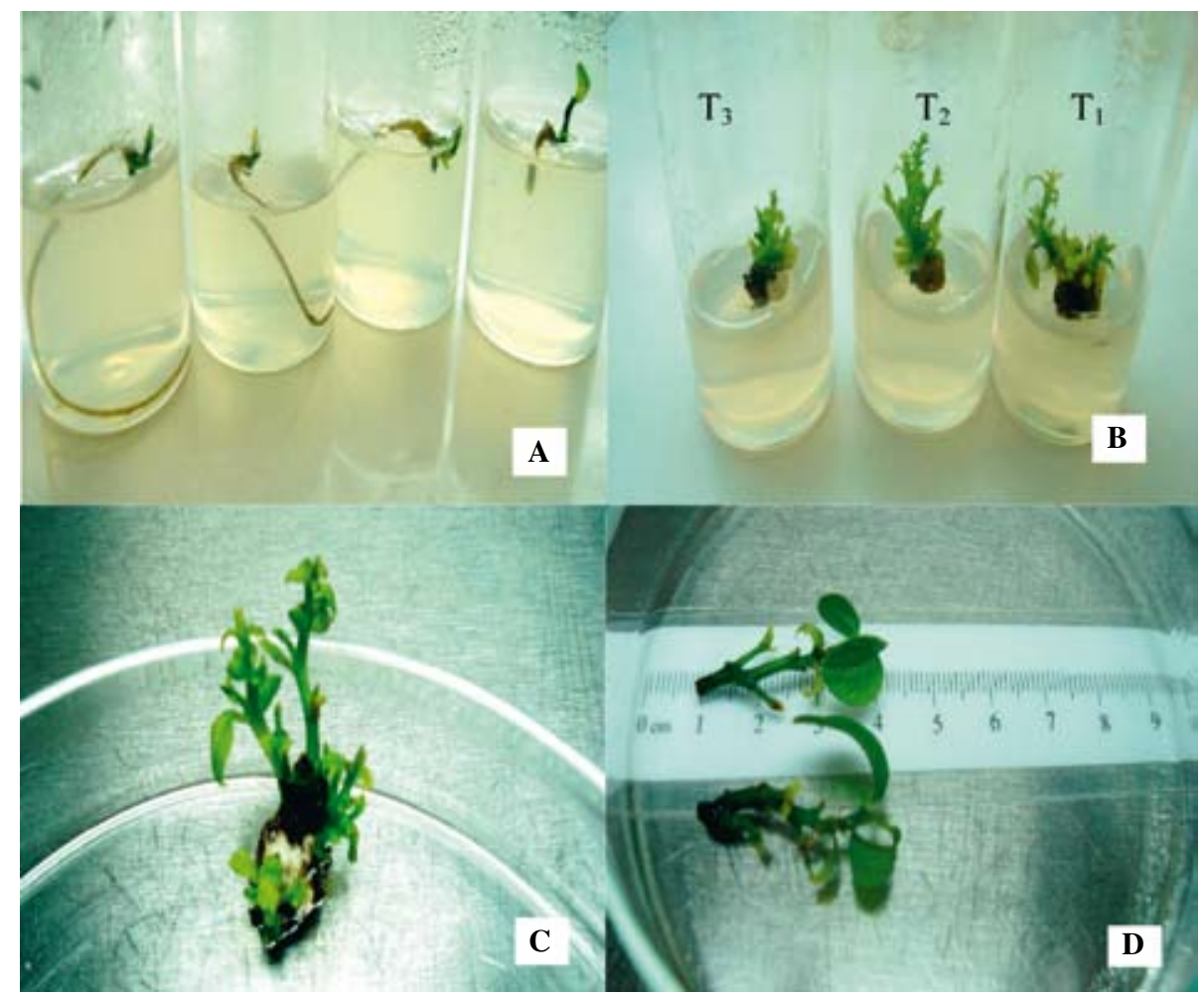

Figura 1. Propagación in vitro de Persea lingue a partir de embriones aislados a los 120 días de cultivo. A) Vitroplantas después de 30 días del establecimiento embrionario en medio MS1/4 libre de hormonas. B) Microtallos en medio de proliferación MS ácido indolbutírico/bencilaminopurina $\left(0,1 / 1,0 ; 0,1 / 2,0 ; 0,5 / 2,0 ; \mathrm{mg} \mathrm{L}^{-1}\right)$. C) Elongación caulinar de microtallos en medio MS suplementado con ácido indolbutírico/bencilaminopurina $\left(0,05 / 0,5 \mathrm{mg} \mathrm{L}^{-1}\right)$. D) Microtallos con características morfofisiológicas adecuadas para la siguiente etapa inducción de enraizamiento in vitro.

In vitro propagation of Persea lingue Ness from isolated embryos after 120 days of growth. A) Vitroplants after 30 days of embryo establishment in hormone free MS1/4 medium. B) Microshoots in MS IBA/BAP $\left(0.1 / 1.0 ; 0.1 / 2.0 ; 0.5 / 2.0 ; \mathrm{mg} \mathrm{L}^{-1}\right)$ proliferation medium. C) Microshoots caulinar elongation in MS medium supplemented with IBA/BAP $\left(0.05 / 0.5 \mathrm{mg} \mathrm{L}^{-1}\right)$. D) Microshoots with adequate morpho-physiological characteristics for the following stage of in vitro rooting induction.

Cuadro 2. Prueba comparativa entre medias de tratamientos generados mediante el procedimiento prueba de rangos múltiples de Duncan.

Comparative test among averages of treatments generated by means of the Duncan's multiple range test.

\begin{tabular}{|c|c|c|c|}
\hline Fases de la micropropagación & Variables & $\begin{array}{l}\text { Factor de estudio Ácido indolbutírico/ } \\
\text { Bencilaminopurina }\left(\mathrm{mg} \mathrm{L}^{-1}\right)\end{array}$ & Media $\pm S$ \\
\hline \multirow{3}{*}{ Proliferación } & Número de yemas & $\begin{array}{l}0,1 / 1,0 \\
0,1 / 2,0 \\
0,5 / 2,0\end{array}$ & $\begin{array}{l}4 \pm 0,7 \mathrm{~b} \\
9 \pm 1,0 \mathrm{a} \\
3 \pm 0,7 \mathrm{~b}\end{array}$ \\
\hline & Número de brotes & $\begin{array}{l}0,1 / 1,0 \\
0,1 / 2,0 \\
0,5 / 2,0\end{array}$ & $\begin{array}{l}4 \pm 0,7 \mathrm{~b} \\
7 \pm 1,0 \mathrm{a} \\
2 \pm 1,0 \mathrm{~b}\end{array}$ \\
\hline & Número hojas & $\begin{array}{l}0,1 / 1,0 \\
0,1 / 2,0 \\
0,5 / 2,0\end{array}$ & $\begin{array}{l}6 \pm 1,0 \mathrm{a} \\
3 \pm 0,7 \mathrm{~b} \\
2 \pm 1,0 \mathrm{~b}\end{array}$ \\
\hline \multirow{3}{*}{ Elongación caulinar (mm) } & Longitud de yema & $\begin{array}{l}0,01 / 0,1 \\
0,05 / 0,5 \\
0,10 / 1,0\end{array}$ & $\begin{array}{l}2,0 \pm 1,0 \mathrm{a} \\
3,5 \pm 0,8 \mathrm{a} \\
4,0 \pm 1,0 \mathrm{a}\end{array}$ \\
\hline & Longitud de brote & $\begin{array}{l}0,01 / 0,1 \\
0,05 / 0,5 \\
0,10 / 1,0\end{array}$ & $\begin{array}{r}16 \pm 6 \mathrm{~b} \\
25 \pm 1,0 \mathrm{a} \\
15 \pm 1,0 \mathrm{~b}\end{array}$ \\
\hline & Longitud de entrenudos & $\begin{array}{l}0,01 / 0,1 \\
0,05 / 0,5 \\
0,10 / 1,0\end{array}$ & $\begin{array}{l}3,0 \pm 0,8 \mathrm{~b} \\
5,0 \pm 1,0 \mathrm{a} \\
2,0 \pm 0,8 \mathrm{~b}\end{array}$ \\
\hline
\end{tabular}

Letras diferentes indican diferencias estadísticamente significativas $(P<0,01)$. 
concentración hormonal de la relación auxina-citoquinina en el medio de cultivo y altas concentraciones de citoquinina favorecieron la inducción y formación de puntos de crecimiento redundando en un incremento en la tasa de proliferación.

Estudio histológico. La secuencia histológica de la diferenciación del brote (figura 2) corrobora el proceso de regeneración in vitro en Persea lingue vía organogénesis directa. Particularmente en la figura 2A, que corresponde a una sección transversal de una protuberancia separada del explante inicial, se aprecia un nivel de organización mayor por la presencia de tejidos como la protodermis y el procambium, los cuales le confieren cierta individualidad a este tipo de estructura debido a que originarán tejidos de tipo epidérmico y primarios.

En las primeras etapas del desarrollo embrionario, usualmente, todas las células están en división. Posteriormente, la proliferación celular se restringe a los nódulos o protuberancias que se van desarrollando e incrementando su nivel de organización, dando lugar a la formación de domos meristemáticos y primordios foliares (figura 2B y 2C) constituyendo de esta forma un meristemo caulinar. Específicamente, la formación de los meristemos caulinares a partir de los nódulos o protuberancias mostró un mayor vínculo con el explante inicial. Asimismo, el tejido vascular del brote estableció conexión con el tejido del cual derivan (figura 2D), lo que indica que son brotes de origen organogénico.

\section{DISCUSIÓN}

Los resultados de este estudio ratifican al cultivo in vitro a partir de embriones maduros como una vía factible y exitosa para masificar poblaciones de Persea lingue. Asimismo, indica que las fitohormonas juegan un rol clave en la regeneración del tejido vascular. Específicamente, un balance apropiado entre auxinas y citoquininas complementadas en el medio nutritivo y las que se encuentran

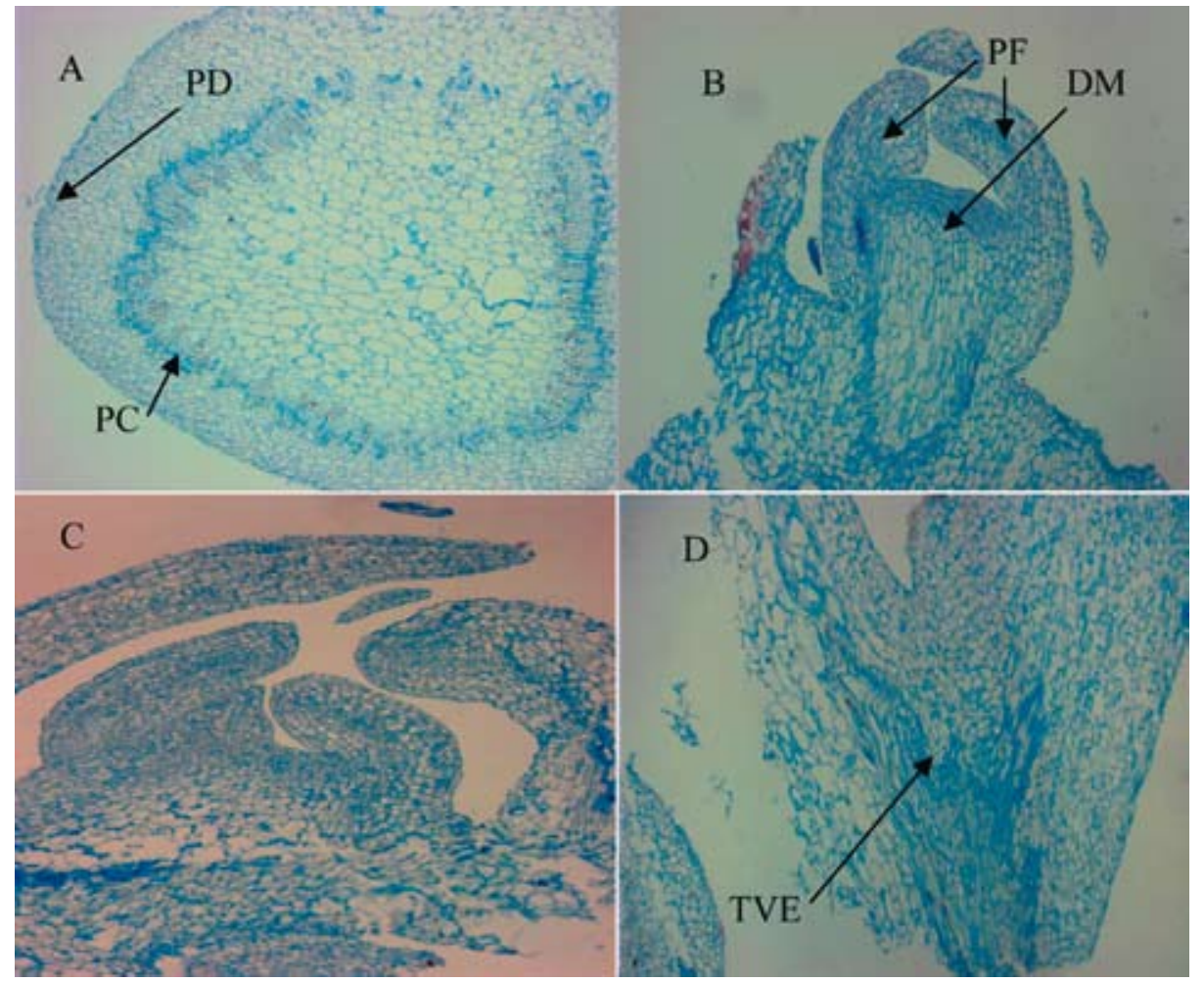

Figura 2. Secuencia histológica de la formación de brotes en secciones apicales de microtallos obtenidos de embriones maduros germinados in vitro. A) Sección transversal de una protuberancia separada del tejido inicial con un alto grado de organización celular, tejido similar a la protodermis (PD) y al procambium (PC). B) Sección longitudinal de una protuberancia separada que muestra la formación del domo meristemático (DM) y la presencia de los primordios foliares en desarrollo (PF) después de 45 días de iniciado el cultivo. C) Sección longitudinal de un ápice caulinar. D) Brote organogénico emergiendo a partir de una yema axial, nótese la conexión directa entre su tejido vascular y el del explante (TVE).

Histological sequence of the formation of apical sections of microshoots obtained from in vitro germinated mature embryos. A) Transversal section of a protuberance separated from the original tissue with a high level of cellular organization, similar tissue to protodermis (PD) and procambium (PC). B) Longitudinal section of a separated protuberance that reveals the formation of the dome meristematic (DM) and the presence of developing leaf primordium (PF) after 45 days of growth. C) Longitudinal section of a caulinary meristem. D) Organogenic shoots emerging from an axial bud; please notice the direct connection between its vascular tissue and the explant tissue (TVE). 
en forma endógena en los explantes cultivados in vitro son esenciales para inducir división y elongación celular (Jiménez 2000, Martínez y Pacheco 2006).

En este estudio el mayor número de yemas y brotes por explante se logró con la dosis hormonal de 0,1/2,0 mg L $\mathrm{m}^{-1}$ de ácido indolbutírico/bencilaminopurina (tratamiento T2) (cuadro 2). Estos resultados concuerdan con los obtenidos en Persea americana Mill por Mohamed-Yasseen (1995) y Pliego-Alfaro y Murashige (1988). Resultados de otros estudios coinciden en que la inducción de órganos por efecto de las citoquininas está orientada a la formación de puntos de crecimiento, logrando éxito en función a proporciones altas de citoquinina con respecto a la auxina.

Específicamente, en varias especies se ha comprobado que a medida que aumenta la concentración de BAP se aprecia una disminución en la longitud de los brotes, incrementándose los índices de proliferación (Sánchez et al. 2002, Rodríguez et al. 2003, Sotolongo et al. 2003). Al respecto, Orellana (1998) señala que el balance auxina-citoquinina es determinante en el coeficiente de proliferación, por lo que optimizar un balance adecuado reflejará elevadas tasas de proliferación, ampliando la efectividad de la técnica de micropropagación. Sin embargo, Pedroza y Micán (2006) señalan que los requerimientos de citoquinina son extremadamente variables y dependen del contenido endógeno de cada especie y tipo de explante.

El meristemo caulinar es una estructura dinámica en la cual, continuamente, se están produciendo crecimiento, división celular y formación de órganos. Concretamente, las hojas se originan como resultado de una serie de divisiones celulares periclinales en los flancos del meristemo y su desarrollo está bajo control de la relación hormonal auxinas y citoquininas (Uribe et al. 2008). Al respecto, los resultados de este estudio indican que concentraciones de 0,1/1,0 $\mathrm{mg} \mathrm{L}^{-1}$ de ácido indolbutírico/bencilaminopurina favorecen el desarrollo de hojas por explante (cuadro 2, figura 1B) a lo largo del cultivo in vitro. Estos resultados no coinciden con los obtenidos por González y Salazar (1984), González et al. (1985) y Barceló-Muñoz et al. (1999) en estudios del género Persea, atribuible al tipo de explante que utilizaron, época de recolección y a las diferencias fisiológicas del material vegetal. Otro factor crítico es la influencia del número de días entre las transferencias en un medio de cultivo fresco. En concentraciones de $1,0 \mathrm{mg} \mathrm{L}^{-1}$ de bencilaminopurina y transferencias a un medio nutritivo fresco cada 21 días favoreció la formación de rosetas y entrenudos cortos (cuadro 2, figura 1B), fundamentándose a la persistencia de un efecto remanente y acumulativo de bencilaminopurina en el subcultivo siguiente, redundando en una deficiente absorción y metabolización por el explante.

La longitud de los brotes y entrenudos se favorece con una menor concentración de citoquininas, fundándose en que se disminuye la división celular y se promueve la elongación del tejido debido a la acción de las auxinas
(Uribe et al. 2008). Lo anterior, coincide con los resultados logrados en este estudio, exhibiendo que la mayor elongación de los brotes y entrenudos de los microtallos se obtuvieron en el tratamiento T2 $\left(0,05 / 0,5 \mathrm{mg} \mathrm{L}^{-1}\right)$ (cuadro 2, figura 1C). Este mejor desarrollo caulinar obtenido se explica por un balance óptimo en la relación auxina-citoquinina. Tamas (1995) señala que el efecto inhibitorio de la elongación caulinar debido a un aumento en la concentración exógena de hormonas es diferencial para cada tipo de hormonas, evidenciándose al variar los niveles en la relación auxina-citoquinina. Al respecto, Von Arnold (1988) señala que es frecuentemente necesario reducir la dosis o eliminar las citoquininas en el medio nutritivo para lograr un incremento en la elongación de los entrenudos, lo cual redundará en la obtención de brotes de mayor longitud.

La evaluación histológica que incluyó cortes transversales y longitudinales corrobora el proceso de regeneración in vitro vía organogénesis directa (figura $2 \mathrm{D}$ ). Por otro lado, evidencia los procesos que implican la formación de nódulos o protuberancias (figura $2 \mathrm{~B}$, figura 2C), observándose que la principal actividad morfogenética de las células sucede en los tejidos que conforman a la región meristemática. Las estructuras meristemáticas son zonas de división y expansión celulares por procesos mitóticos. La función básica de la mitosis dentro de un proceso morfogenético es la formación de un número definido de células en división activa, las cuales son capaces de responder a señales de desarrollo (Villalobos y Thorpe 1991).

La formación de tejidos con actividad morfogenética se inicia a partir de células poco diferenciadas (Lara et al. 2003), obedeciendo a diversos factores tales como el tipo de explante. En este estudio, la formación de zonas con actividad morfogenética ocurrió en la proximidad de los tejidos como el procambium (figura 2A), donde se asume que la concentración de los reguladores de crecimiento es mayor. Lo anterior, se atribuye por las altas concentraciones de auxinas en las regiones meristemáticas que están en crecimiento activo. Además, el tejido procambial, por procesos posteriores, producirá los tejidos conductores primarios.

\section{CONCLUSIONES}

El cultivo in vitro de Persea lingue a partir de secciones apicales de microtallos, utilizando como material vegetal inicial embriones maduros, reflejó resultados exitosos, afirmando los primeros cimientos científicos como una alternativa potencial conducente a aminorar algunas de las problemáticas de propagación que afronta esta especie nativa chilena. Asimismo, este estudio, pionero en implicar a esta especie, evidencia la viabilidad en las fases de proliferación y elongación caulinar como etapas clave en el proceso de propagación vía organogénesis in vitro. 


\section{AGRADECIMIENTOS}

Al Programa Internacional de Becas del International Fellowships Fund (IFF) de la Fundación Ford por la beca otorgada al primer autor para realizar estudios de doctorado en la Universidad Austral de Chile. A la Escuela de Graduados de la Facultad de Ciencias Forestales y Recursos Naturales por el financiamiento parcial otorgado para la adquisición de productos químicos en la fase experimental. Al personal investigador de GenFor S.A. por las facilidades, comentarios y sugerencias durante el desarrollo de la fase experimental.

\section{REFERENCIAS}

Barceló-Muñoz A, C Encina, E Pérez, F Pliego-Alfaro. 1999. Micropropagation of adult avocado. Plant Cell 58: 11-17.

Bennett A. F. 1998. Linkages in the landscape: the role of corridors and connectivity in wildlife conservation. Gland, Switzerland and Cambridge, U.K. IUCN. 254 p.

Bustamante R, I Serey, ST Pickett. 2003. Forest fragmentation, plant regeneration and invasion processes across edges in Central Chile. In Bradshaw G, P Marquet eds. How landscapes change. Human disturbance and ecosystem fragmentation in the Americas. New York, USA. SpringerVerlag. p. 145-160.

Bustamante R, C Castor. 1998 The decline of an endangered temperate ecosystem: the ruil (Nothofagus alessandrii) forest in central Chile. Biological Conservation 7: 1607-1626.

Donoso C. 1974. Dendrología, árboles y arbustos chilenos. Manual $\mathrm{N}^{\mathrm{o}}$ 2. Santiago, Chile. Universidad de Chile. $142 \mathrm{p}$.

Donoso C, B Escobar. 2006. Autoecología de las especies latifoliadas: Persea lingue Ness. In Donoso C ed. Las especies arbóreas de los bosques templados de Chile y Argentina. Autoecología. Valdivia, Chile. Ediciones Marisa Cuneo. p. 501-509.

Echeverría C, D Coomes, J Salas, JM Rey-Benayas, A Lara, AC Newton. 2006. Rapid deforestation and fragmentation of Chilean temperate forests. Biological Conservation 130: 481-494.

Escobar B, C Donoso. 1998. Técnicas de vivero y plantación para lingue (Persea lingue). Documento Técnico No 115. Santiago, Chile. Chile Forestal. 13 p.

González R, G Salazar. 1984. Root induction and vegetative development from avocado plantlets (Persea americana Mill). Calif. Avocado Soc. Yrbk. 68: 167-171.

González R, G Salazar, V Vázquez. 1985. Propagation in vitro of Chinini (Persea schiedeana Ness). Calif. Avocado Soc. Yrbk. 69: 125-131.

Hartmann H, D Kester. 1999. Propagación de plantas: Principios y prácticas. México D.F., México. Compañía Editorial Continental. $760 \mathrm{p}$.

Jiménez E. 2000. Cultivo de ápices y meristemos. In Pérez P ed. Propagación y mejora genética de plantas por biotecnología.
Santa Clara, Cuba. Instituto de Biotecnología de las Plantas. p. 45-56.

Lara A, R Valverde, L Gómez. 2003. Histología de embriones somáticos y brotes adventicios inducidos en hojas de Psychotria acuminata. Agronomía Costarricense 27(1): 37-48.

Martínez M, J Pacheco. 2006. Protocolo para la micropropagación de Furcraea microphylla Baker. Agronomía Colombiana 24(2): 207-213.

Mohamed-Yasseen Y. 1995. In vitro propagation of avocado (Persea americana Mill.). Calif. Avocado Soc. Yrbk. 79: 107-111.

Murashige T, F Skoog. 1962. A revised medium for rapid growth and bioassays with tobacco tissue cultures. Physiol. Plant. 15: 473-497.

Orellana P. 1998. Introducción a la propagación masiva. In Pérez JN ed. Propagación y mejora genética de plantas por biotecnología. Santa Clara, Cuba. Instituto de Biotecnología de las Plantas. p. 125-132.

Pedroza J, Y Micán. 2006. Asymbiotic germination of Odontoglossum gloriosum (Orchidaceae) under in vitro conditions. In Vitro Cell. Dev. Biol. Plant. 42(6): 543-547.

Pliego-Alfaro F, T Murashige. 1988. Somatic embriogénesis in avocado (Persea americana Mill.) in vitro. Plant Cell 12: 61-66.

Rodríguez R, O Matthei, M Quezada. 1983. Flora arbórea de Chile. Concepción, Chile. Universidad de Concepción. 408 p.

Rodríguez R, M Daquinta, I Capote, D Pina, Y Lezcano, J González. 2003. Nuevos aportes a la micropropagación de Swietenia macrophylla x Swietenis mahogami (Caoba híbrida) y Cedrela odorata (cedro). Cultivos tropicales 24(3): 23-27.

Sánchez N, V Rebolledo, M Mata. 2002. Inducción de brotación múltiple en Diospyros riojae por medio del cultivo de tejidos vegetales. Forezta veracrusana 4: 41-46.

Sotolongo R, M García, L Junco, G Geada, E García. 2003. Micropropagación de Psidum salutare (Myrtaceae). Revista del Jardín Botánico Nacional 24(1-2): 245-250.

Tamas IA. 1995. Hormonal regulation of apical dominance. In Davies PJ ed. Plant hormones. Physiology, biochemistry and molecular biology. Dordrecht, The Netherlands. Kluwer Academic Publisher. p. 572-597.

Uribe M, C Delaveau, M Garcés, R Escobar. 2008. Efecto de asepsia y fitohormonas en el establecimiento in vitro de Berberidopsis corallina, a partir de segmentos nodales. Bosque 29(1): 58-64.

Villalobos V, T Thorpe. 1991. Micropropagación: conceptos, metodología y resultados. In Roca WM, LA Mrogrinski eds. Cultivo de tejidos en la agricultura. Fundamentos y aplicaciones prácticas. Cali, Colombia. Centro Internacional de Agricultura Tropical. p. 127-142.

Von Arnold S. 1988. Tissue culture methods propagation of forest trees. Newsletter (Holland) 1(56): 1-13.

Recibido: 09.09.09

Aceptado: 30.06 .10 